This document was prepared in conjunction with work accomplished under Contract No. DE-AC09-96SR18500 with the U.S. Department of Energy.

This work was prepared under an agreement with and funded by the U.S. Government. Neither the U. S. Government or its employees, nor any of its contractors, subcontractors or their employees, makes any express or implied: 1 . warranty or assumes any legal liability for the accuracy, completeness, or for the use or results of such use of any information, product, or process disclosed; or 2 . representation that such use or results of such use would not infringe privately owned rights; or 3 . endorsement or recommendation of any specifically identified commercial product, process, or service. Any views and opinions of authors expressed in this work do not necessarily state or reflect those of the United States Government, or its contractors, or subcontractors. 


\title{
Analysis of Turbulent Mixing Jets in Large Scale Tank
}

\author{
Si Y. Lee, Richard A. Dimenna, Robert A. Leishear, and David B. Stefanko \\ Savannah River National Laboratory \\ Washington Savannah River Company
}

Aiken, SC 29808

si.lee@srnl.doe.gov; richard.dimenna@srnl.doe.gov; robert.leishear@srnl.doe.gov; david.stefanko@srnl.doe.gov

\begin{abstract}
Flow evolution models were developed to evaluate the performance of the new advanced design mixer pump for sludge mixing and removal operations with high-velocity liquid jets in one of the large-scale Savannah River Site waste tanks, Tank 18. This paper describes the computational model, the flow measurements used to provide validation data in the region far from the jet nozzle, the extension of the computational results to real tank conditions through the use of existing sludge suspension data, and finally, the sludge removal results from actual Tank 18 operations.
\end{abstract}

A computational fluid dynamics approach was used to simulate the sludge removal operations. The models employed a three-dimensional representation of the tank with a two-equation turbulence model. Both the computational approach and the models were validated with onsite test data reported here and literature data. The model was then extended to actual conditions in Tank 18 through a velocity criterion to predict the ability of the new pump design to suspend settled sludge. A qualitative comparison with sludge removal operations in Tank 18 showed a reasonably good comparison with final results subject to significant uncertainties in actual sludge properties.

\section{INTRODUCTION}

Tank 18 is a 1.3 million-gallon capacity, single-wall waste tank located in the F-Tank Farm at Savannah River Site (SRS). It was placed into service as a receiver of low radioactive decay heat waste. The tank is an 26 m diameter flat-bottomed, domed roof, cylindrical carbon steel tank with a height of about $10.4 \mathrm{~m}$ with no cooling coils or internal supports. The waste in the tank was originally salt and 
sludge, but the salt has been dissolved and transferred to other tanks. The remaining sludge was hydraulically re-suspended and transferred to other tanks.

SRS has successfully used numerous slurry pump designs from different manufacturers over the last 25 years to mix the contents of radioactive waste storage tanks $[1,2,4]$. One of these slurry pump designs is the Advanced Design Mixer Pump (ADMP) built by Lawrence Pumps, Inc [2] and is schematically shown in Fig. 1. ADMP is a 16.76-m long shaft, vertical pump, which includes a top mounted motor, a rotating turntable, a segmented drive shaft, a centrifugal impeller, and a pipe column that surrounds the shaft and suspends the pump inside the tank. Power is provided to the motor through slip rings to permit the pump to rotate continuously at $1 / 5$ to $1 / 4 \mathrm{rpm}$. A smaller separate motor drives the turntable. Shaft sections are coupled together between the motor and the impeller at the bottom of the pump. Enclosing the shaft, the column contains pressurized water to prevent diffusion of waste into the column through the lower seal and out onto the upper tank surface through the upper seal. These mechanical seals are mounted to the drive shaft at the top and bottom of the pump to contain the pressure in the column. Typically, several pumps are inserted into the waste tanks through $0.57 \mathrm{~m}$ diameter cylindrical openings, referred to as risers, and mounted to the rotating turntables. Once installed in a waste tank, the pumps act as mixers by drawing nuclear waste into the pump suction and discharging a high velocity stream of liquid back into the tank. The discharge stream, or jet, entrains waste as it expands into the tank and lifts sedimented waste, called sludge, from the tank bottom. 


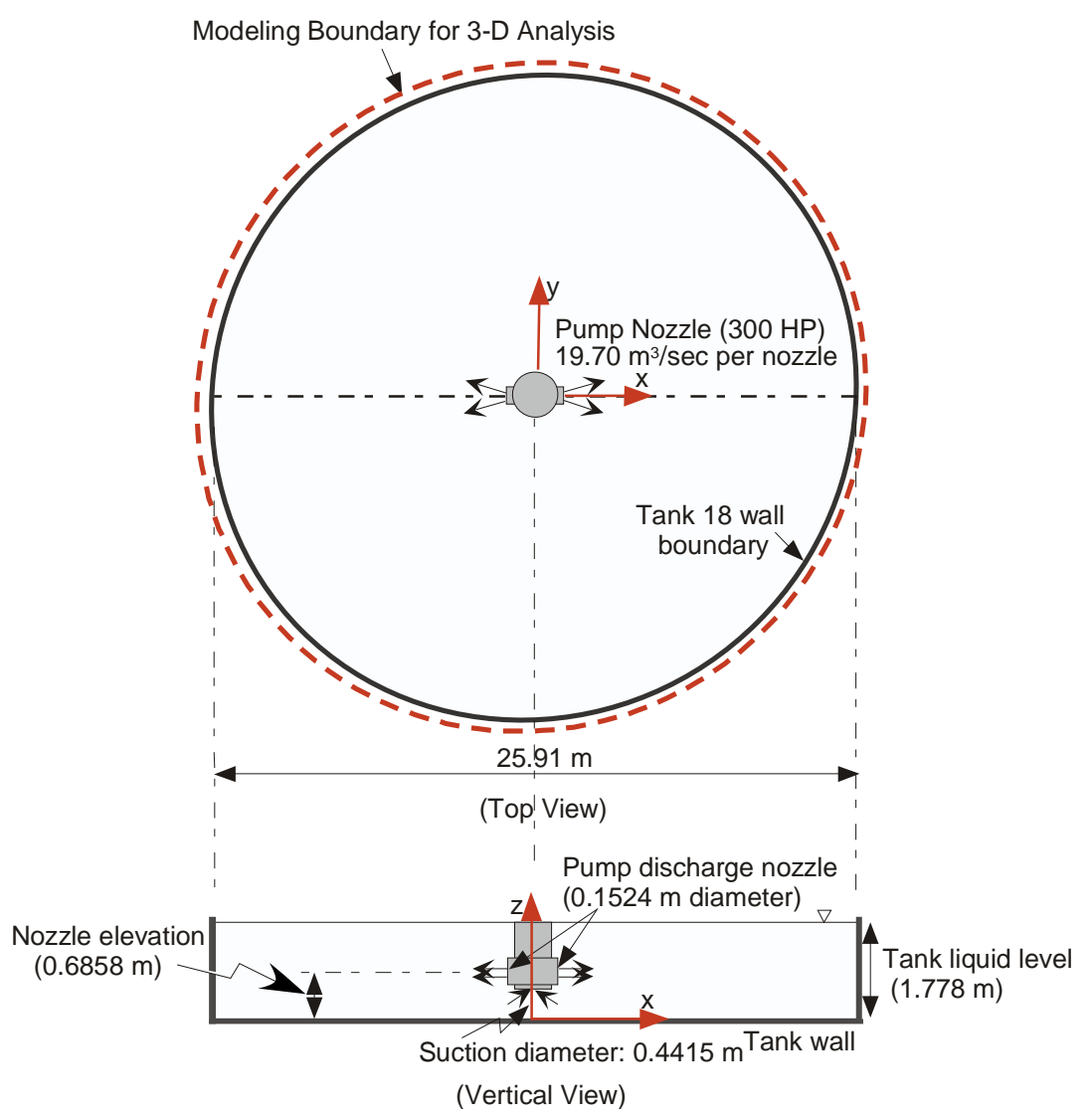

Figure 1 Schematic of tank operation system showing the present modeling boundary and slurry mixing pump

To suspend the settled sludge, water was added to Tank 18 as a slurry medium and the ADMP was used to suspend the sludge. The pump has a bottom suction and two opposing discharge nozzles as shown in Fig. 1. Each nozzle is $0.1524 \mathrm{~m}$ in diameter. Performance is $19.7 \mathrm{~m}^{3} / \mathrm{min}$ (per nozzle) at $1185 \mathrm{rpm}$ and $15.85 \mathrm{~m}$ of head. The nozzle discharge velocity is $17.98 \mathrm{~m} / \mathrm{sec}$. The pump suction and nozzle diameters are $0.44 \mathrm{~m}$ and $0.15 \mathrm{~m}$, respectively. The pump is immersed in the sludge layer, allowing a recirculating mixture of sludge and water to serve as the feed flow. The pump is located in the center of Tank 18. The cleaning pattern generated on the tank bottom when the pump rotates defines the effective cleaning radius (ECR). A maximum cleaning distance can be defined when the pump is stationary, and this distance is also used as the ECR. After the ADMP suspends the sludge, the waste is transferred to another tank. Detailed operating conditions are summarized in Table 1. Waste removal operating conditions were discussed in the previous work [4], with the tank liquid level maintained at about $1.78 \mathrm{~m}$ as shown in Fig. 1. 
This paper has two main objectives. The first is to document the extension of empirically observed sludge suspension performance in the form of an effective cleaning radius to other pumps or tank conditions by computational methods. The second objective is to document the benchmark data used to validate the computational method and models used to accomplish this goal, since the data gathered for that purpose extend the literature to include high velocity jet data at distances far from the jet nozzle.

To accomplish these objectives, local velocity measurements were made for the discharge jet of a submerged ADMP in a 26-m diameter full scale tank, known as the Full Tank Facility (FTF) to establish the flow patterns induced by the jet. At the same time, a computational model containing the ADMP mixer used in FTF was developed. The model was validated by benchmarking it against the full scale test data [1]. It was then used to evaluate flow patterns in the Tank 18 and estimate the cleaning capabilities of the ADMP. Sensitivity analyses were performed to investigate the influence of key operating parameters. In addition, a smaller mixer pump design with a 0.0762-m nozzle diameter was evaluated as shown in Table 1. A schematic diagram for the Tank 18 system used in the analysis is illustrated in Fig. 1. The analysis results were used to evaluate hydraulic cleaning operations and provide information that assisted in developing the operating plan for Tank 18 waste removal. The results also helped identify special requirements for sampling and monitoring the sludge suspension.

Although turbulent jets have been studied extensively, the specific configuration needed for this evaluation has not received much attention: horizontally-oriented nozzle exits with one bottom suction located near the bottom of a large scale tank. A multi-dimensional model employing the $k-\varepsilon$ model for turbulence was used to compute near-/far-field entrainments in turbulent liquid jets in the tank. Flow measurements were made to provide validation data for prototypic tank size and conditions for the benchmarking analysis. The computed results are compared with test results measured in the far downstream field more than 60 nozzle diameters from the jet pump, since test data and analysis for regions farther than about 40 nozzle diameters from the pump are not available in the literature. It is noted that local velocities along the center-line are about $40 \%$ lower than the existing literature correlation in the far 
field, in agreement with the measured results. The near-field predicted values of center-line velocity are reproduced within about $15 \%$.

This paper will first discuss the detailed computational approach, since this lays the foundation for evaluating the applicability of the far-field jet velocity measurements for benchmark applications. The discussion will include experimental setups, data acquisitions for FTF tests, descriptions of the computational approaches, and benchmarking results. Applications of the benchmarked model to the simulations of the Tank 18 mixing operations to evaluate the hydraulic cleaning capabilities of the ADMP mixer submerged inside the tank follow.

Table 1. Reference design and operating conditions used for the analysis of Tank 18 model

\begin{tabular}{|c|c|c|}
\hline \multicolumn{2}{|c|}{ Parameters } & Conditions \\
\hline \multicolumn{2}{|c|}{ Tank dimensions $\left(\mathrm{D}_{\text {tank }} \times \mathrm{H}_{\text {tank }}\right)$} & $25.91 \mathrm{~m}$ diameter x $1.78 \mathrm{~m}$ liquid level (or $1.02 \mathrm{~m} \mathrm{high}^{+}$) \\
\hline \multicolumn{2}{|c|}{ Mixing Pump } & ADMP \\
\hline \multicolumn{2}{|c|}{ Number of nozzles per pump } & 2 \\
\hline \multicolumn{2}{|c|}{ Pump nozzle diameter } & $0.1524 \mathrm{~m}$ (or $0.0762 \mathrm{~m}^{+}$) \\
\hline \multirow{2}{*}{$\begin{array}{l}\text { Pump } \\
\text { position }\end{array}$} & Vertical & $0.6858 \mathrm{~m}\left(0.5842 \mathrm{~m}^{+}\right)$above tank bottom \\
\hline & Horizontal & Center \\
\hline \multicolumn{2}{|c|}{ Tank fluid temperature } & $20^{\circ} \mathrm{C}$ \\
\hline \multirow{2}{*}{\multicolumn{2}{|c|}{ Tank fluid }} & Water \\
\hline & & Slurry $^{+}$(SG: 1.2 , viscosity: 2 сp) \\
\hline \multicolumn{2}{|c|}{ Flowrate for each nozzle } & $19.70 \mathrm{~m}^{3} / \mathrm{min}$ for ADMP $\left(9.84 \mathrm{~m}^{3} / \mathrm{min}^{+}\right)$ \\
\hline \multicolumn{2}{|c|}{ Nozzle velocity $\left(\mathrm{U}_{\mathrm{o}}\right)$} & $17.98 \mathrm{~m} / \mathrm{sec}$ \\
\hline \multicolumn{2}{|c|}{ Pump orientation } & Indexed operation \\
\hline
\end{tabular}

Note: ${ }^{+}$This is for the sensitivity run.

\section{COMPUTATIONAL APPROACH}

The fundamental model presented here is that of a turbulent jet submerged near the bottom of a large tank. The distant tank wall serves as an important flow boundary, even though it is far removed from the 
pump discharge nozzle. The focus of the present work is to evaluate the ability of the ADMP to suspend sludge in Tank 18. Prior to discussing the experimental setup and modeling approaches, the literature results for a free turbulent jet flow are reviewed briefly, since the free jet flow is similar in many respects to the bounded wall jet.

\subsection{Model development}

2.1.1 Steady-state model. Previous work [3] and literature data [5] show that when a turbulent jet is discharged from a nozzle with a diameter $d_{0}$, it both entrains fluids and expands. Most mixing action and entrainment takes place in the region of fully-developed flow which begins at a distance of approximately eight nozzle diameters from the exit plane. The non-dimensional velocity distribution $\varphi_{v}$ along the jet axis of this region for a homogeneous fluid jet is given by [5]

$\varphi_{v}=\left(\frac{u}{U_{o}}\right)=C_{o}\left[\frac{x}{d_{o}}\right]^{-1}=C_{o} \eta^{-1}$

In Eq. (1), $C_{0}$ is a constant determined by the turbulence characteristics of the jet, $U_{0}$ the nozzle exit velocity, and $\mathrm{x}$ the distance from nozzle. Abramovich (1963) correlated experimental data for a free turbulent jet submerged in fluid using the non-dimensional form provided by Eq. (1). From his work, the proportionality constant $\mathrm{C}_{\mathrm{o}}$ was determined to be 6.32 . It shows that the velocity at any point in the region of established flow is directly proportional to the product, $d_{0} \cdot U_{0}$. Thus, the axial entraining distance corresponding to minimum entrainment velocity can be estimated with nozzle diameter and flow rate. Kiser [6] measured a centerline velocity and studied axial velocity behavior and the spreading of the turbulent jet up to the distance range of 10 to 40 diameters from the nozzle jet submerged in water. All other previous works [6-9] were related to the near-field flow characteristics and entrainments of the turbulent jets.

The present work is primarily focused on the decay of the axial jet velocity and the evolution of flow patterns for the far-field region from the pump nozzle, since local flow patterns in the remote regions near the wall boundary are important for sludge suspension and mixing operations in a large tank. The fluid domain for the tank has both a solid boundary and a free surface boundary as the jet expands into the downstream region and ultimately recirculates via the suction on the bottom of the pump as shown in Fig. 
1. The spreading fluid is retarded by the interaction with the wall, and the inner part of the flow may be expected to show a certain structural similarity to a boundary layer. Entrainment of quiescent fluid occurs near the outer edges of the flow, and accordingly resembles a free jet.

A measure of the ability to shear the sludge layer, the scouring wall shear, is directly related to the local fluid velocity. The initial movement of solids deposited on the bottom of the tank identifies the critical condition or initial scour. It is usually described by two criteria, the minimum flow velocity and the frictional shear to scour and initiate movement of the solids particles deposited on the bottom of waste tank. From these two criteria and the fact that the sludge in Tank 18 contains a range of 5 to $10 \mu \mathrm{m}$ of fine particles [3,4], a local fluid velocity can be determined as a performance indicator for adequate mixing or suspension of sludge materials.

When liquid flow passes over a stationary cohesive sludge mound containing solid particles, the flow results in hydrodynamic forces being exerted on individual particles in the mound. For the initial movement of the top layer of the mound, the degree of erosion resistance for a given particle to the hydrodynamic forces of the flowing fluid depends on the cohesion and adhesion forces. An increase in the fluid momentum causes an increase in the magnitude of the hydrodynamic forces. Hence, for a particular stationary sludge mound, a condition is eventually reached at which particles in the movable bed are not able to resist the hydrodynamic forces and solids in the top layer start to erode.

The literature data [10] show that large particles are more easily eroded by streams than smaller ones. This phenomenon is more pronounced with small particles since the cohesive forces increase with decreasing size. Figure 2 shows for each particle size a certain velocity below which it will experience sedimentation, and a critical scour velocity, above which it will be eroded. Fluid velocity between these two velocities will transport solids of that size. The literature data [11] show that fluid velocity, particle size, specific gravity of particle, and tank liquid level are key parameters associated with particle suspension. It should be emphasized that the incipient velocity of erosion is actually dependent on the critical shear stress at which settled sediment begins to move. The critical shear stress of the cohesive 
materials in Tank 18 depends on the composition of the sludge material, the particle-size distribution, particle shape, and packing. A minimum fluid velocity for suspending cohesive sludge at Savannah River Site (SRS) has been confirmed and established as $0.7 \mathrm{~m} / \mathrm{sec}(2.27 \mathrm{ft} / \mathrm{sec})$.[12] Figure 2 shows that this velocity, $0.7 \mathrm{~m} / \mathrm{sec}$, will erode the sludge layer for the particle sizes larger than clay material (about $5 \mu \mathrm{m}$ ). Establishing this characteristic velocity for SRS sludge allows the local fluid velocity at any distance from the nozzle to be employed as a measure of the slurrying capability of the ADMP.

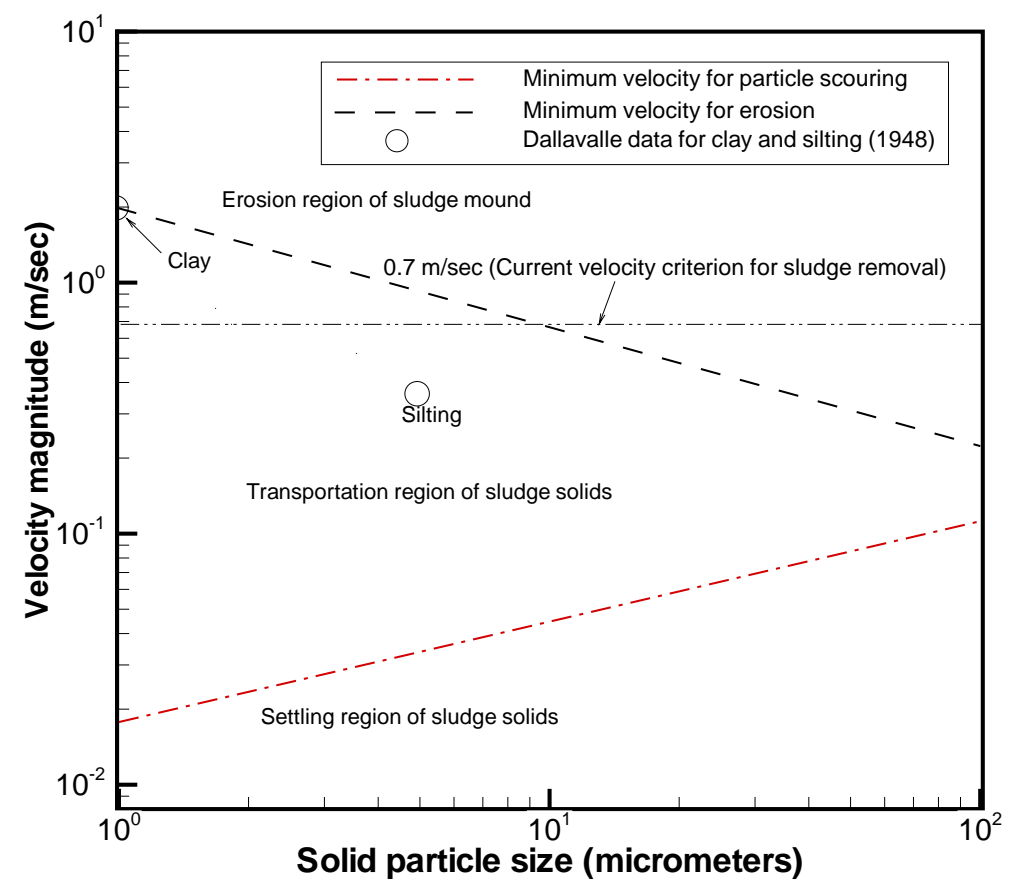

Figure 2. Velocity criteria for deposition, scouring, and erosion of sludge solids based on Graf's correlation [11] and Dallavalle's data [10]

Two types of materials are identified in Tank 18, both of which are discussed in detail in the previous work [12]. One is particulate zeolite. The sizes of the zeolite particles in the tank are between 300 to 700 micrometers [13]. Because it's fast settling, it can be suspended by the slurry pumps, but it cannot be effectively removed from the tank using a discharge pump. The other material is sludge, which can be removed because it remains in suspension longer. Unfortunately there are scant data available for particle dimensions in the sludge. However, studies of the ECR based on measured yield stress and density provide 
reasonable estimates for both the ECR and the velocity at the ECR required to suspend sludge. A complete discussion of material properties and their relationship to the minimum required velocity of $0.7 \mathrm{~m} / \mathrm{sec}$ is provided in the previous work [12]. In this work the velocity criterion required for the flow stream to shear the waste into suspension was discussed in detail by the theoretical and experimental basis. The work also provided SRS data for sludge settling velocities.

2.1.2 Transient model. The transient model used to estimate the time needed for steady-state flow development was an extension of the steady-state model. The difficulty of modeling pump rotation accurately and the anticipated computational time penalty to be incurred pointed to using a quasi-steady approach.

To represent transient behavior in the large tank, the model was run in transient mode for twenty seconds in a fixed pump orientation. For an actual rotation speed of $1 / 4 \mathrm{rpm}$, this was the time required for a 30 degree rotation. The orientation of the pump was then rotated 30 degrees and the calculation was restarted from the final conditions of the previous run. The transientl was then run for another twenty seconds and the pump was rotated another 30 degrees. This resulted in a 180 degree rotation being modeled in six steps to represent two minutes of operation. The flow patterns generated were compared with each other to determine when they started repeating, an indication that a steady flow pattern had been achieved for the rotating pump condition. The patterns were also compared with the qualitative observations from the flow measurements used as benchmark data for then model.

\subsection{Computational Model Validation}

The analysis consists of two major parts. One part is to develop a model for the test facility used to simulate Tank 18 to benchmark the calculations with no sludge mounds. The second part is to calculate the flow patterns for the turbulent jet induced by the mixer and to estimate the extent of the slurry mixing zone in Tank 18. Flow obstructions such as a cohesive sludge mound are also considered based on the fluid velocity that would be developed at the sludge mound if the tank bottom were clean. Erosion of the sludge surface is not addressed.

The modeling work considers four basic cases with different boundary conditions to investigate how sensitive the flow patterns are to different tank liquid levels and pump elevations. Flow patterns were calculated to evaluate the effects on jet dissipation and suspension efficiency. A three-dimensional CFD 
approach was used to calculate velocity distributions for the fluid domain in tank. A commercial finite volume code, FLUENT [18], was used to create a prototypic geometry file in a non-orthogonal mesh environment. The model geometry was created using a body-fitted coordinate system and structured multiblock grids. Reference design conditions including the mixing pump and fluid properties are given in Table 1. The ADMP (6-inch nozzle) was compared to a theoretical pump having a smaller nozzle diameter of 3 inches as a sensitivity study.

Detailed wave motion of the free surface at the top of the tank was neglected for computational efficiency. That behavior does not have a significant impact on the flow patterns inside the slurry region in a deep tank [19]. The fluid properties of water were evaluated at room temperature $\left(20^{\circ} \mathrm{C}\right)$. The flow conditions for the pump operations are assumed to be fully turbulent since Reynolds numbers for typical operating conditions are in the range of $10^{8}$ based on the pump nozzle conditions. A standard two-equation turbulence model, the $k-\varepsilon$ model [20], was used since benchmarking results against literature data [21] showed that the $k-\varepsilon$ model predicts turbulent flow evolution in a large stagnant fluid domain with reasonable accuracy. Figure 3 compares predictions for four different two-equation models and the Reynolds stress model (RSM) with test results available in the literature. Although RSM has the potential to give more accurate results for flows in which streamline curvature, swirl, rotation, or rapid changes near the wall boundary might be important, the standard $k-\varepsilon$ model is considered a good model for mixing calculations over a large fluid domain such as Tank 18. The results demonstrate that the standard $k-\varepsilon$ model combined with standard wall functions generally predicts the test results better than other models. Its predictions agree with the data within about $15 \%$.

This model specifies the turbulent or "eddy" viscosity $\mu_{t}$ by the empirical equation.

$$
\mu_{t}=\left(\frac{C_{\mu} \rho_{f} k^{2}}{\varepsilon}\right)
$$

In the present calculations, $C_{\mu}$ is 0.09 [20]. The turbulent viscosity is computed by solving two transport equations for turbulent kinetic energy $(k)$ and dissipation rate of turbulent energy $(\varepsilon)$. The governing equations to be solved include one continuity equation, three momentum equations for the three component 
directions ( $\mathrm{x}, \mathrm{y}$, and $\mathrm{z}$ directions), and two modeled transport equations for the two turbulence quantities, namely $k$ and $\varepsilon$.

Water was used to simulate the fluid in the tank assuming that it would give an acceptable representation of the flow patterns. Sensitivity studies were performed using other fluid properties for an indexed pump model, i.e., the pump in a fixed radial direction.

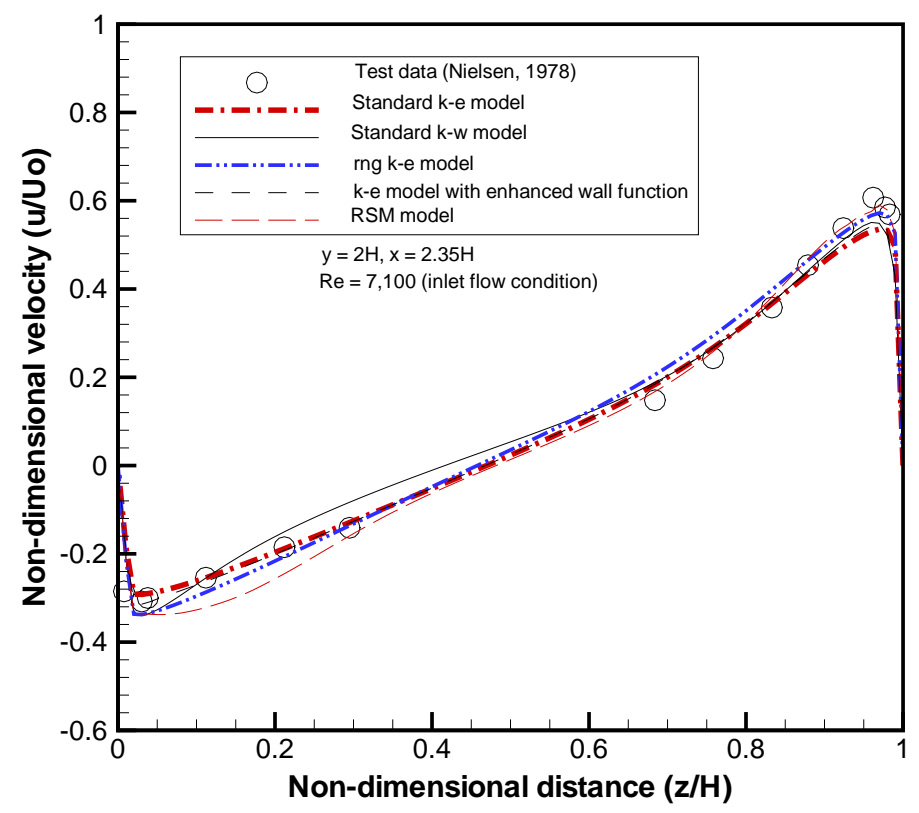

Figure 3. Comparisons of modeling predictions for different turbulence models against the literature data [21]

\subsection{Modeling Results}

Three-dimensional flow models were developed and the modeling calculations benchmarked against SRS test results. The benchmarked model was applied to the estimation of flow circulation patterns within Tank 18 and the investigations of steady-state and transient flow responses. Initially, a two-dimensional approach was in an attempt to capture the qualitative flow phenomena associated with the mixing behavior of the jet at a significantly reduced computational time. The results of the two-dimensional calculation were not even qualitatively correct. They overestimated the flow velocity by more than $40 \%$ when 
compared to test results. The flow patterns predicted by the 2-D model were different from the 3-D modeling results and experimental observations with a stagnation point calculated in an incorrect location. These results stemmed directly from the 2-D approximation, partly from neglecting the presence of the tank bottom, partly from the two-dimensional model not having the ability to capture viscous dissipation due to vertical flow rotation, and partly from the requirement that the return flow path be in the plane of the r- $\theta$ calculation. The impact of the viscous dissipation term is shown mathematically in the fluid momentum equation,

$\rho \frac{D \vec{v}}{D t}=-\nabla p-\nabla \bullet \tau+\rho \vec{g}$

from which the viscous term can be expanded as

$$
\begin{aligned}
(\nabla \bullet \tau)_{\text {shear }} & =\mu \nabla \bullet(\nabla \vec{v}) \\
& =\mu \nabla(\nabla \bullet \vec{v})-\mu \nabla \times(\nabla \times \vec{v}) \\
& =\mu \nabla(\nabla \bullet \vec{v})-\mu \nabla \times \vec{\Omega}
\end{aligned}
$$

In Eq. (3), $\mu$ is dynamic viscosity and $\vec{\Omega}$ is the vorticity related to the fluid rotation. The first term on the right-hand side of Eq. (3) is associated with fluid compressibilty, and the second term is related to the vortex formation generated by the evolution of jet flow. For an incompressible liquid, the first term is zero. In the vorticity term, motion related to $\Omega_{x}$ and $\Omega_{y}$ cannot be captured, since these two components are zero in a two-dimensional model.

A sensitivity analysis for different number of mesh nodes was performed to examine numerical uncertainty due to the various spatial discretizations for a range of $1.0 \times 10^{5}$ to $1 \times 10^{6}$ nodes. From a nodalization study, an optimum number of about 260,000 nodes was established. The optimum number was determined by the criterion that the numerical results be independent of mesh sizes within about $5 \%$ uncertainty. In this case, minimum mesh sizes, less than about $5 \mathrm{~mm}$ long, were used near the nozzle exit 
and suction inlet regions to capture the high velocity gradients in these locations. Sensitivity results for three different meshes along the primary axial direction of jet pump are compared in Fig. 4.

The simulation results showed that jet flows from the two nozzles were dissipated quickly along the principal discharge directions. As soon as the flow exits the nozzle, four main circulation cells are generated in the tank, one on each side of the centerline for each nozzle. Within about 10 seconds after starting, the nozzle facing the center of the tank created two dominant cells, but after that, all four cells developed to about the same size. Transient flow path lines created using the Lagrangian integral method along the flow direction are shown in Fig. 5. These circulating flow patterns were consistent with the qualitative flow patterns observed by the FTF tests, and this information helped to understand the suspension and removal of waste sludge.

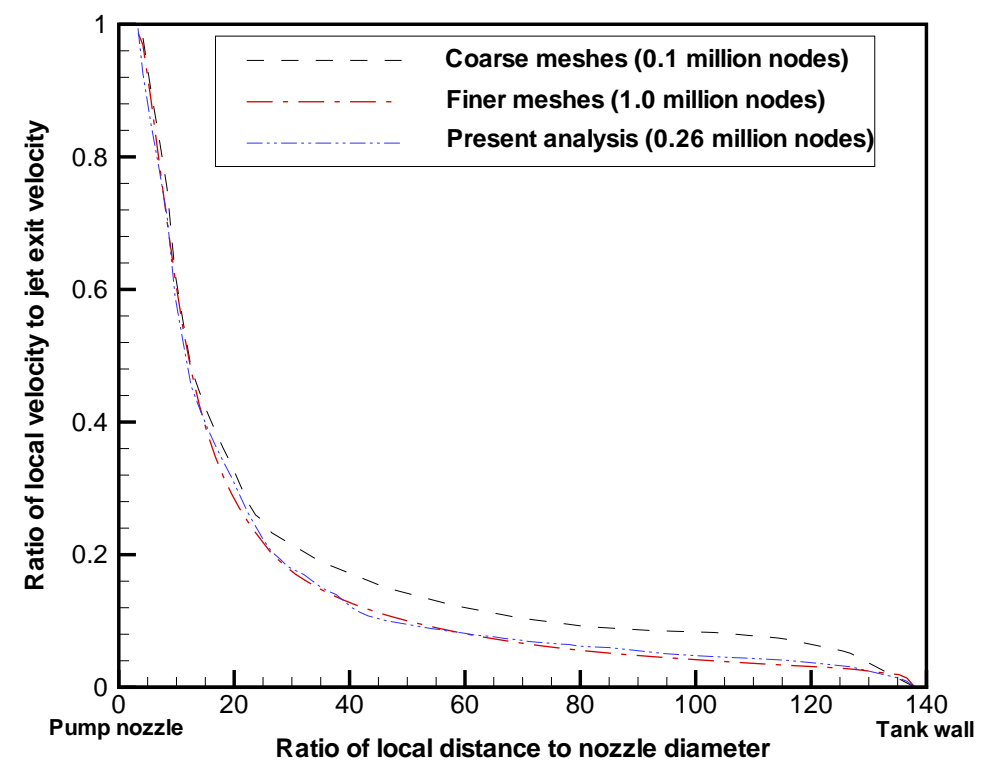

Figure 4. Mesh sensitivity results of the Full Tank facility model 




Figure 5. Flow paths around the tank at $\mathbf{1 0}$ seconds after the start of the pump on the discharge plane of the Full Tank facility with stationary pump for the initially quiescent tank

\section{TEST DESCRIPTION AND MODEL VALIDATION}

\subsection{Experimental Setup and Data Acquisitions}

The Full Tank Facility (FTF) used the ADMP built by Lawrence pumps, Inc. [14] for the sludge mixing test. The ADMP is a $16.764 \mathrm{~m}$ long pump as shown in Fig. 6. The pump is made up of several shaft sections and column sections. Each column section is individually removable and has one thrust bearing, one radial bearing, and one splined shaft. Column sections are bolted together at flanges. Bearings are oil lubricated and fed by the individual bearing housing. Shaft sections connect to each other by flexible couplings. The column was filled with dried filtered air while installed at both FTF and when later installed in the waste tank. Air containment is achieved through mechanical seals, metal o-rings, and graphite gaskets. The ADMP column is made up of 16 and 18 NPS, Schedule 40 pipe. The pump has a 0.9906-m diameter casing, a 0.4572-m diameter mixed flow impeller, and a 300 HP, 6-pole induction motor. Figure 6 is a sketch of the pump casing and the two nozzles which are part of the casing. Each nozzle is $0.1524 \mathrm{~m}$ in diameter and faces an opposing direction. The pump performance is $19.70 \mathrm{~m} / \mathrm{min}^{3}$ per nozzle at $1185 \mathrm{rpm}$ and $15.85 \mathrm{~m}$ of head. The nozzle discharge velocity is about $17.98 \mathrm{~m} / \mathrm{sec}$.

To set up the ADMP for the flow experiment, the pumping system was mounted to an overhead platform at the test facility as shown in Fig. 6. A turntable supplied with the pump was first mounted to the 
overhead structural steel platform that spaned the $25.91 \mathrm{~m}$ diameter by $2.4384 \mathrm{~m}$ deep tank. Two column sections were removed from the pump to shorten the length to meet the structural steel mounting requirements of the full tank facility, and the ADMP was then bolted to the turntable. The closest horizontal distance between the pump centerline and tank wall was 4.88 meters. The nozzle centerline height to the tank floor was $0.6858 \mathrm{~m}$ as shown in Fig. 6.

Fluid velocities were measured using the walkway over the FTF tank as shown in Fig. 6. The walkway spanned the distance from the tank wall to a pole at the tank center and could be repositioned by rotating the walkway about the tank centerline. Measurements were obtained using a Marsh McBirney model 511 [15] electromagnetic velocity probe. The probe was bolted to a steel rod braced between the walkway and the tank bottom to prevent vibration of the velocity probe.

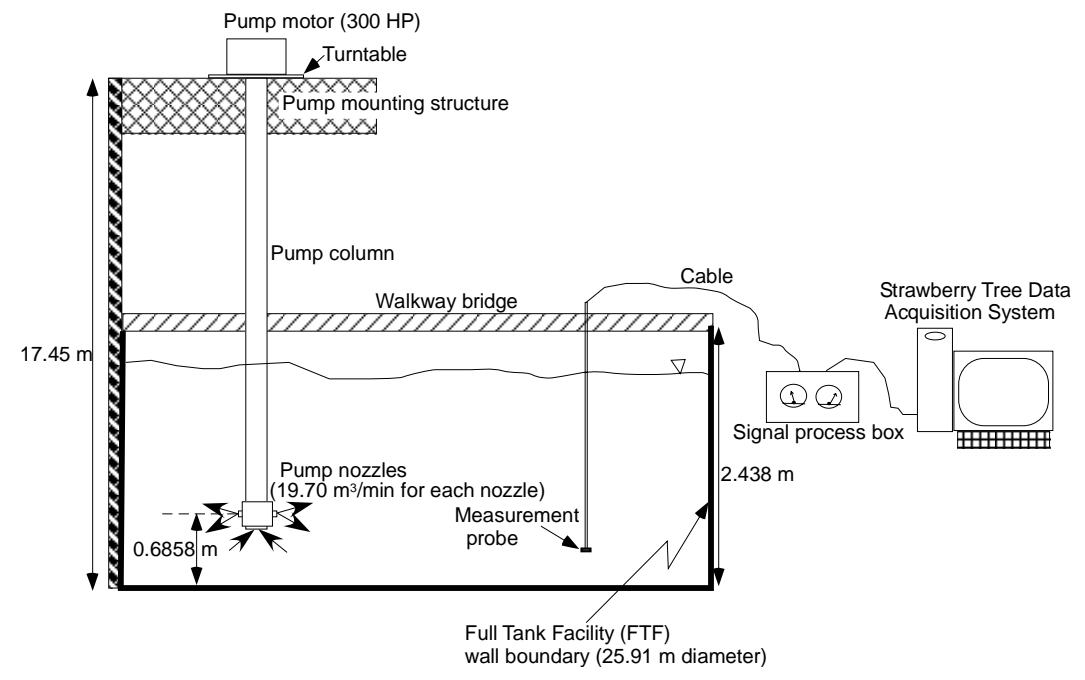

Figure 6. Schematic of experimental setup for the flow measurement at Full Tank Facility (FTF)

The calibrated Marsh McBirney equipment $[2,15,16]$ was used to collect velocity data. The equipment consisted of a transducer probe, cable, and signal processor housed in a portable case. The instrument sensed two dimensional flows in a plane normal to the longitudinal axis of the electromagnetic sensor, which was parallel to the tank bottom. The panel meters provided visual observation of flow, while the consequent analog output voltages were recorded with a Strawberry Tree data acquisition system [17] at 10 
$\mathrm{Hz}$ for 3 minutes. The full scale output range of velocity components is $+/-0.300 \mathrm{~m} / \mathrm{second}$ when measured along the orthogonal $\mathrm{X}$ and $\mathrm{Y}$ axes of the electromagnetic sensor. The probe was positioned to ensure that one of the two axes was normal to the pump centerline. The $\mathrm{X}$ and $\mathrm{Y}$ velocity vectors were then added to obtain an absolute velocity. 1800 discrete velocity measurements were obtained at each data point over a three minute time span.

Numerous data locations were selected to capture an array of velocities across the pump discharge jet to assess whether the ADMP could effectively suspend sludge. Velocities were measured on the discharge plane of the pump and close to the tank bottom. The flow measurements were taken with the ADMP operating at its full discharge speed of $17.98 \mathrm{~m} / \mathrm{sec}$ and the test tank filled to a $1.78 \mathrm{~m}$ (70 inch) liquid level. The pump was held at a fixed position (i.e., without the turntable moving) throughout the tests. Fluid velocities were measured at both $0.076 \mathrm{~m}$ (3 inches) and $0.68 \mathrm{~m}$ (27 inches) from the tank bottom at the locations. mapped in Fig. 7.

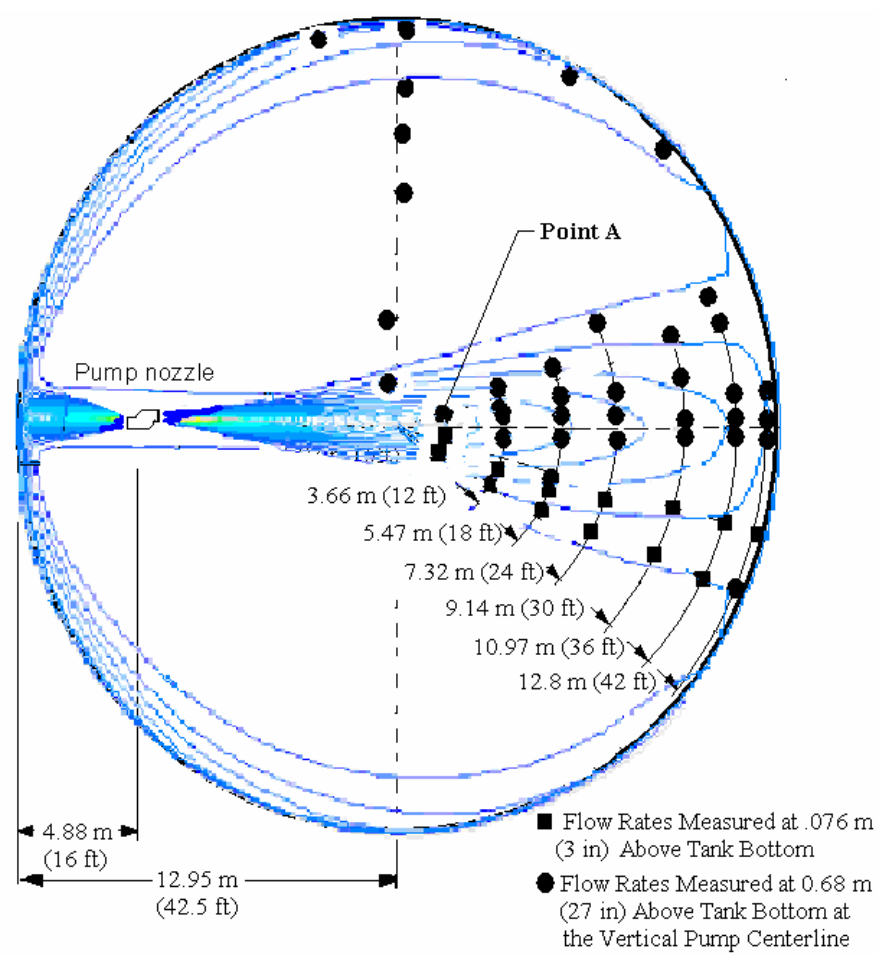

Figure 7. Velocity measurement data points 


\subsection{Flow Test Results}

A total of 64 sets of velocity measurements were obtained at the mapped locations as shown in Fig. 7. All the test results were used for benchmarking the CFD model and hey compared favorably. The data reduction techniques are discussed here.

The test data fluctuated sinusoidally, a result of the installed pump oscillating about its axis through a $\pm 10^{\circ}$ angle with a period of about 10 seconds. Because of this oscillation, the average of the peak data readings was thought to be a better measure of the actual axial velocity data than the arithmetic average of the data. Point A (Fig. 7) was arbitrarily selected for discussion. The velocity data associated with this point are shown in Fig. 8. The data are observed to reach a well defined maximum every 10 seconds. This observation corresponded to the situation when the sensor was aligned directly with the primary discharge flow. Consequently, only the data near the peak value were used for the analysis. To obtain a single peak average value, the parallel and normal velocity components were simply added vectorially at each data point and averaged. As noted above, the velocity probe was mounted to a braced steel rod but it still vibrated at approximately $80 \mathrm{~Hz}$. These vibrations had a negligible effect on flow measurements, since they were averaged with respect to the velocity measurement. Similar results for the flow measurements throughout the tank are plotted in Fig. 9 using peak data averages.

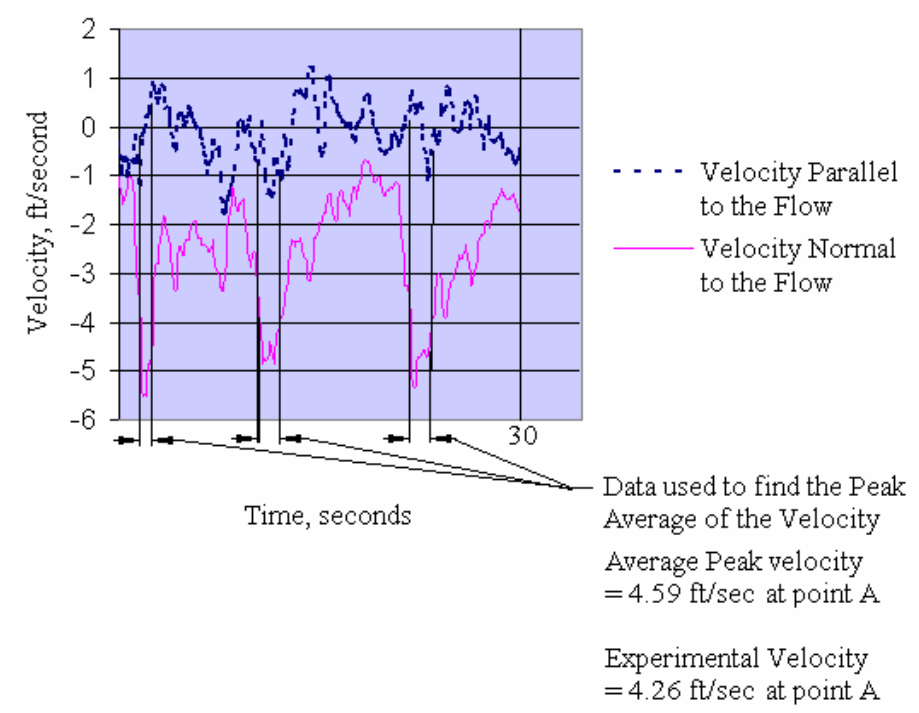

Figure 8. Velocity data at an arbitrary point in the flow $(1 \mathrm{ft} / \mathrm{sec}=0.3048 \mathrm{~m} / \mathrm{sec})$ 
As might be expected, the deviations between the peak and arithmetic averages decrease as the distance from the pump increases. Factors such as proximity to the tank bottom and wall, return flow, and distance from the nozzle tend to diminish the effect of oscillations in the nozzle orientation in the fardownstream region. The test results are in agreement with the modeling predictions to within about $25 \%$, as will be shown later. The on-axis measured data are closer in magnitude to the CFD predictions at a distance from the pump than are the off-axis measurements. For example, the experimental velocity for Point A is compared to a least squares fit of the test data along with the predictions in Fig. 9. All the test results obtained along the principal discharge direction in the horizontal plane of the pump nozzle are in agreement with the least squares fit results within about $6 \%$, and with the modeling predictions within about $10 \%$. Flow velocities were also measured at locations less than $25^{\circ}$ from the pump discharge direction, but the comparisons were not as good.

The effects of the 180-degree pump rotation on the flow patterns at a distance from the pump could not be effectively measured. However, qualitative observations of the jet in the FTF tank clearly indicated that the jet tends to bend slightly during rotation. This bending of the jet causes an asymmetrical flow pattern similar to that predicted in the CFD models. Figure 10 shows the typical effects of pump rotation on the flow patterns. Further details were provided by Lee and Dimenna [3].

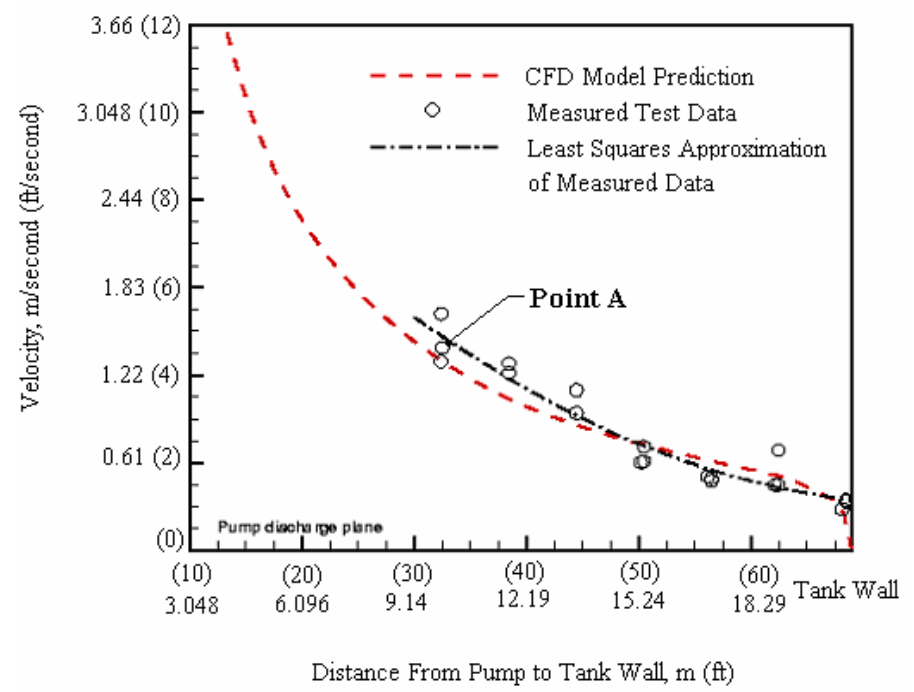

Figure 9. Comparison of the FTF data to the CFD predictions on the pump discharge plane and velocity measurement location, Point A shown in Fig. 7 


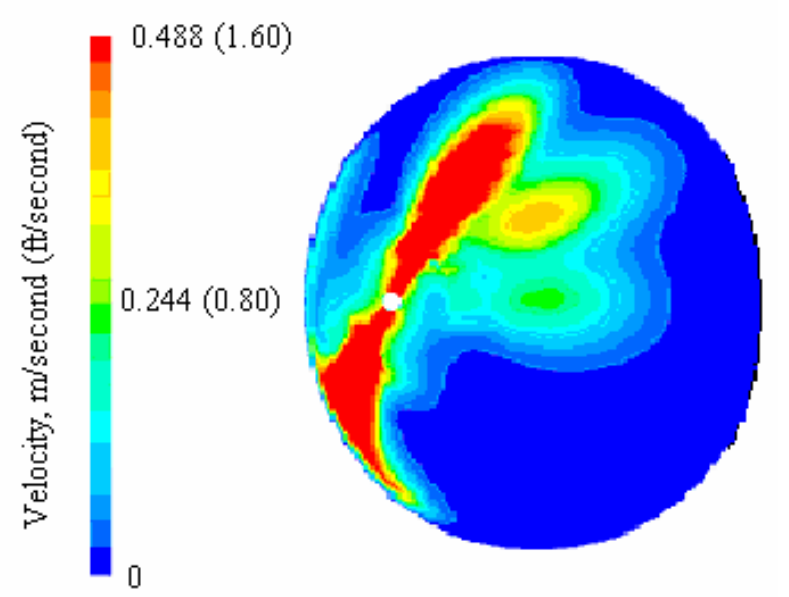

Figure 10. Flow patterns one minute after the pump starts with the pump rotating counterclockwise

\subsection{Comparison of CFD Results to Experimental Results}

The results of the three-dimensional calculation are compared with the test results near the center of the discharge direction of the nozzle. The combination of all results in both measurement planes are in agreement with the test data to within about $25 \%$. The model predictions were also compared to test data measured at locations less than $25^{\circ}$ from the discharge direction at the $0.0762-\mathrm{m}$ elevation. The calculated results agree with these data to within about $20 \%$ as shown in Fig. 11. The model results in the discharge plane are also benchmarked against literature data for the high velocity region not far from the nozzle exit. The predictions of fluid velocity along the axial direction of the jet in this plane agree with the data within about $10 \%$ as shown in Fig. 9.

Figure 12 compares the model predictions with all the test data obtained by Full Tank facility. Several data points at remote locations far away from the central axis of the jet flow are significantly higher than the predictions, but the absolute velocities are much smaller than the minimum suspension velocity for zeolite observed in plant operations $(\sim 0.4877 \mathrm{~m} / \mathrm{sec})$. The differences are due to secondary flows created by pump oscillations and flow obstructions neglected in the computational model. The results show that jet velocity decays quickly near the exit of the nozzle due mainly to the turbulent dissipation through the fluid medium. All the test results and modeling predictions are compared quantitatively in Table 2 . Figure 13 
shows an empirical correlation and test data for free and wall jets available in the literature $[4,11]$. Test data for the downstream region farther than 40 jet diameters from the pump are not available in the literature. The results in the figure show that the measured velocities along the center-line are about $40 \%$ lower than the existing literature correlation in the far field, in agreement with the results predicted by the Fluent ${ }^{\mathrm{TM}}$ calculation.

Overall flow patterns for various transient times were computed assuming that the pump was stationary and waste fluid in the FTF tank was initially quiescent. Transient results along the axial flow direction on the pump discharge plane are presented nondimensionally in Fig. 14. The results demonstrated that steady state flow patterns driven by the ADMP were established in about 2 minutes. This is consistent with experimental observations.

The verified model was then used to evaluate the hydraulic cleaning capabilities of the ADMP for sludge removal based on the flow evolution of waste slurry under various operating conditions in Tank 18.

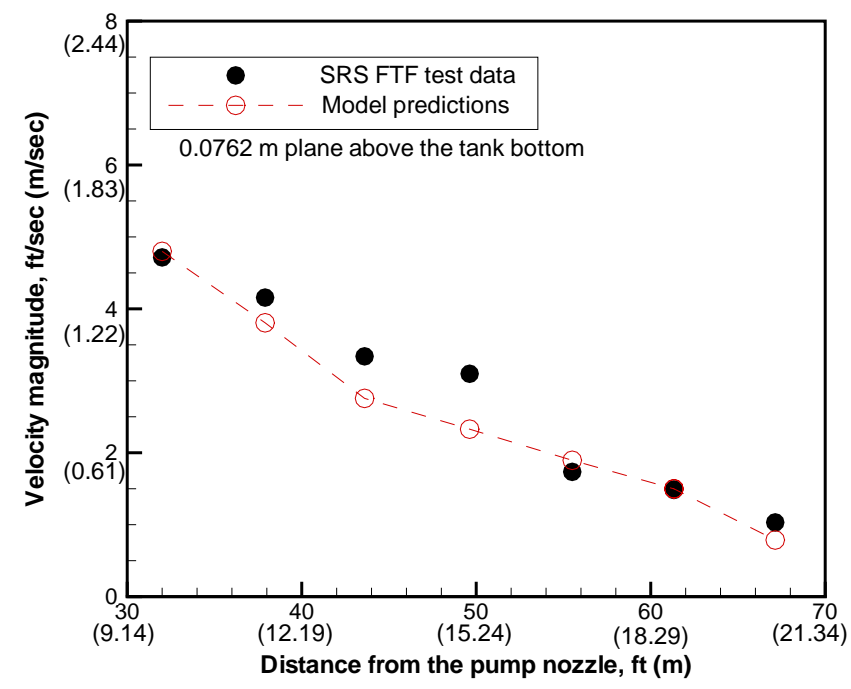

Figure 11. Comparison of the Full Tank Facility model predictions of the discharge velocities with the test data near the centerline of the pump discharge direction at the plane $0.0762 \mathrm{~m}$ above the tank bottom. 




Figure 12. Comparison of the Full Tank facility model predictions with all of the Full Tank facility test data in terms of local velocity nondimensionalized with pump exit velocity 
Table 2. SRS FTF test results compared with the predictions for $0.0762 \mathrm{~m}$ and $0.6858 \mathrm{~m}$ elevations above the tank bottom

\begin{tabular}{|c|c|c|c|c|c|c|c|}
\hline Test No.* & $\begin{array}{c}\text { Experiments } \\
(\mathrm{m} / \mathrm{sec})\end{array}$ & $\begin{array}{c}\text { Predictions } \\
\text { (m/sec) }\end{array}$ & \% Error & Test No.* & $\begin{array}{c}\text { Experiments } \\
\text { (m/sec) }\end{array}$ & $\begin{array}{c}\text { Predictions } \\
\text { (m/sec) }\end{array}$ & \% Error \\
\hline 03r06t-23.7 & 1.437 & 1.463 & 1.8 & $27 \mathrm{r} 18 \mathrm{t}+17.68$ & 0.308 & 0.482 & 56.5 \\
\hline 03r06t-31.8 & 1.481 & 1.270 & -14.2 & $27 r 18 t+3.58$ & 1.115 & 0.924 & -17.2 \\
\hline 03r12t-18.24 & 1.267 & 1.160 & -8.4 & 27r24t-2.69 & 0.619 & 0.780 & 26.0 \\
\hline 03r12t-26.34 & 1.204 & 0.831 & -31.0 & $27 r 24 t+2.69$ & 0.725 & 0.780 & 7.6 \\
\hline 03r18t-18.24 & 1.018 & 0.840 & -17.5 & $27 \mathrm{r} 24 \mathrm{t}+16.79$ & 0.352 & 0.475 & 35.0 \\
\hline 03r18t-24.58 & 1.069 & 0.799 & -25.3 & $27 \mathrm{r} 24 \mathrm{t}+8.69$ & 0.612 & 0.670 & 9.4 \\
\hline 03r24t-15.59 & 0.944 & 0.710 & -24.8 & 27r24t-15.59 & 0.724 & 0.540 & -25.3 \\
\hline 03r24t-23.69 & 0.565 & 0.440 & -22.1 & $27 r 24 t+89.59$ & 0.468 & 0.318 & -32.1 \\
\hline 03r30t-15.05 & 0.529 & 0.578 & 9.3 & 27r30t-2.15 & 0.502 & 0.611 & 21.6 \\
\hline 03r30t-23.15 & 0.384 & 0.348 & -9.4 & $27 r 30 t+2.15$ & 0.484 & 0.611 & 26.2 \\
\hline 03r36t-14.66 & 0.452 & 0.457 & 1.1 & $27 r 30 t+8.69$ & 0.513 & 0.533 & 4.0 \\
\hline 03r36t-22.76 & 0.407 & 0.297 & -27.1 & $27 r 30 t+16.25$ & 0.318 & 0.357 & 12.3 \\
\hline $03 r 42 t-14.66$ & 0.315 & 0.240 & -23.7 & $27 r 30 t+89.05$ & 0.273 & 0.219 & -19.6 \\
\hline $27 r 12 t+5.34$ & 1.298 & 1.106 & -14.8 & 27r30t-23.15 & 0.662 & 0.360 & -45.6 \\
\hline $27 r 06 t+10.8$ & 1.311 & 1.335 & 1.8 & 27r30t-15.05 & 0.577 & 0.450 & -22.0 \\
\hline $27 r 06 t+15.9$ & 0.866 & 1.250 & 44.4 & 27r36t-1.79 & 0.699 & 0.543 & -22.3 \\
\hline $27 \mathrm{r} 06 \mathrm{t}+16.8$ & 0.947 & 1.219 & 28.7 & $27 \mathrm{r} 36 \mathrm{t}+1.76$ & 0.453 & 0.543 & 19.7 \\
\hline 27r06t-10.8 & 1.646 & 1.335 & -18.9 & $27 r 36 t+15.86$ & 0.572 & 0.396 & -30.7 \\
\hline 27r06t-5.34 & 1.409 & 1.399 & -0.7 & $27 r 36 t+7.76$ & 0.454 & 0.463 & 2.0 \\
\hline 27r06t-23.7 & 1.162 & 1.111 & -4.4 & 27r36t-14.66 & 0.357 & 0.360 & 0.8 \\
\hline 27r06t-31.8 & 1.245 & 1.000 & -19.7 & $27 \mathrm{r} 36 \mathrm{t}+88.66$ & 0.383 & 0.299 & -21.9 \\
\hline $27 \mathrm{r} 06 \mathrm{t}+97.7$ & 0.566 & 0.219 & -61.2 & $27 r 36 t+22.76$ & 0.411 & 0.251 & -39.1 \\
\hline $27 \mathrm{r} 12 \mathrm{t}+11.34$ & 0.771 & 0.997 & 29.3 & $27 \mathrm{r} 42 \mathrm{t}-1.53$ & 0.349 & 0.282 & -19.3 \\
\hline $27 \mathrm{r} 12 \mathrm{t}+19.44$ & 0.648 & 0.770 & 18.8 & $27 \mathrm{r} 42 \mathrm{t}+1.53$ & 0.338 & 0.282 & -16.7 \\
\hline $27 \mathrm{r} 12 \mathrm{t}-18.24$ & 1.229 & 0.945 & -23.1 & $27 \mathrm{r} 42 \mathrm{t}+7.76$ & 0.672 & 0.376 & -44.0 \\
\hline 27r12t-26.34 & 1.050 & 0.674 & -35.8 & $27 r 42 t-14.43$ & 0.485 & 0.302 & -37.8 \\
\hline 27r12t-5.34 & 1.230 & 1.106 & -10.1 & $27 \mathrm{r} 42 \mathrm{t}-22.56$ & 0.201 & 0.180 & -10.5 \\
\hline $27 r 12 t+92.24$ & 0.440 & 0.130 & -70.5 & $27 \mathrm{r} 42 \mathrm{t}+42.63$ & 0.178 & 0.169 & -5.4 \\
\hline 27r18t-3.58 & 0.956 & 0.924 & -3.4 & $27 \mathrm{r} 42 \mathrm{t}+69.53$ & 0.280 & 0.300 & 7.3 \\
\hline 27r18t-24.58 & 0.805 & 0.450 & -44.1 & $27 r 42 t+88.43$ & 0.649 & 0.534 & -17.6 \\
\hline 27r18t-16.48 & 0.969 & 0.678 & -30.1 & $27 \mathrm{r} 42 \mathrm{t}+7.53$ & 0.285 & 0.278 & -2.7 \\
\hline $27 r 18 t+11.34$ & 0.532 & 0.747 & 40.4 & $27 r 42 t+107.53$ & 0.740 & 0.644 & -13.0 \\
\hline
\end{tabular}

Note:* First two digit is for elevation height in foot, second two digit for radial distance in foot from the tank center, and the last one after the alphabet $t$ stands for clockwise (minus sign) or counter clockwise (addition sign) azimuthal angle from the principal discharge direction of the pump nozzle. 


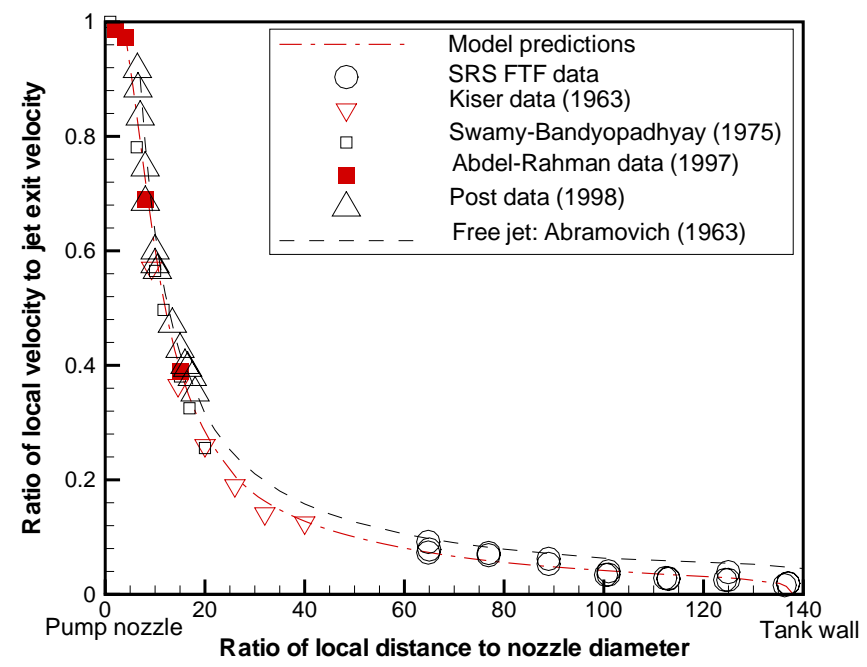

Figure 13. Benchmarking results of the present model against the SRS FTF test data and literature data



Figure 14. Transient velocity distributions along the principal discharge direction for various transient times after the start of the pump on the discharge plane of the Full Tank facility with stationary pump for the initially quiescent tank 


\subsection{Flow Patterns Following Pump Startup}

As shown in Fig. 14, transient flow behavior was examined to evaluate the development of the cleaning distance from a fixed pump. Flow patterns observed at the FTF were simulated by modeling a stepwise $0.25 \mathrm{rpm}$ counterclockwise pump rotation. Transient flow results for the full tank model at the discharge plane were published in SRS technical report [3]. The modeling results showed that the jet flow extended to about $5.8 \mathrm{~m}$ from the nozzle within about 2 seconds, and that it reached the tank wall about 10 seconds after pump start in initially quiescent fluid.

Steady-state flow patterns were established within about 2 min. The steady-state flow patterns on the horizontal discharge plane follow a series of parabolic curves similar to that of a free jet as shown in Fig. 15. The horizontal velocity distributions on the discharge plane of pump nozzle are shown as function of distance from the pump nozzle. Vertical velocity profiles are changed from a bell-shaped curve near the exit of the nozzle to a near-uniform velocity near the tank boundary as shown in Fig. 16. These are consistent with literature data $[11,15]$. The results show that when the pump is located $0.6858 \mathrm{~m}$ above the tank floor, the local velocity reduces to the $0.70 \mathrm{~m} / \mathrm{sec}$ minimum sludge removal velocity at about $12.19 \mathrm{~m}$ distant from the nozzle exit, corresponding to 80 times the nozzle diameter. 


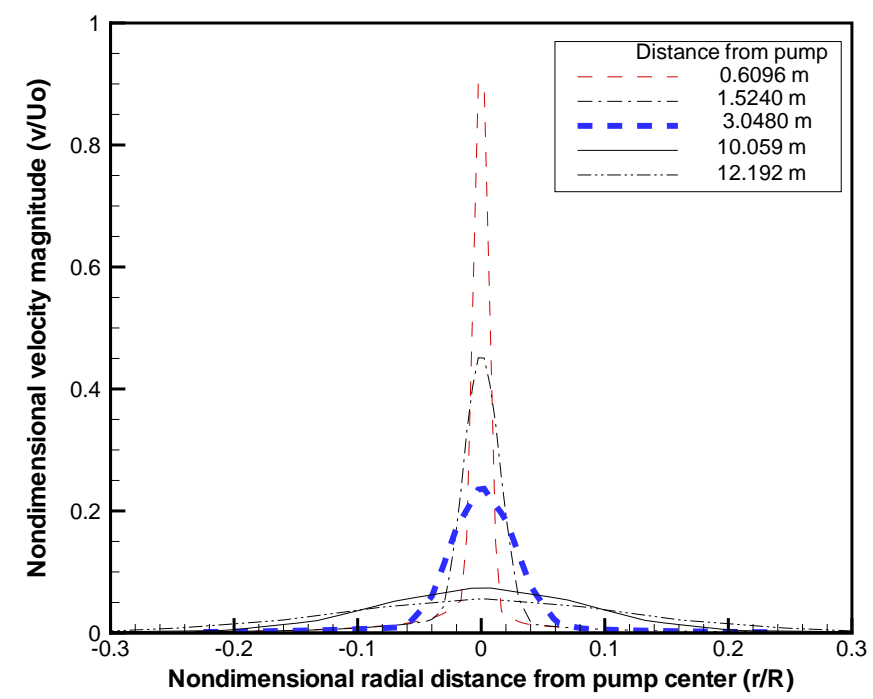

Figure 15. Steady-state nondimensional horizontal velocity profiles for various distances from the pump at the nozzle discharge plane $(0.6858 \mathrm{~m}$ above tank bottom): 3D Model Results for the Full Tank Facility with $1.778 \mathrm{~m}$ liquid level (pump exit velocity Uo $=17.98 \mathrm{~m} / \mathrm{sec}$ )

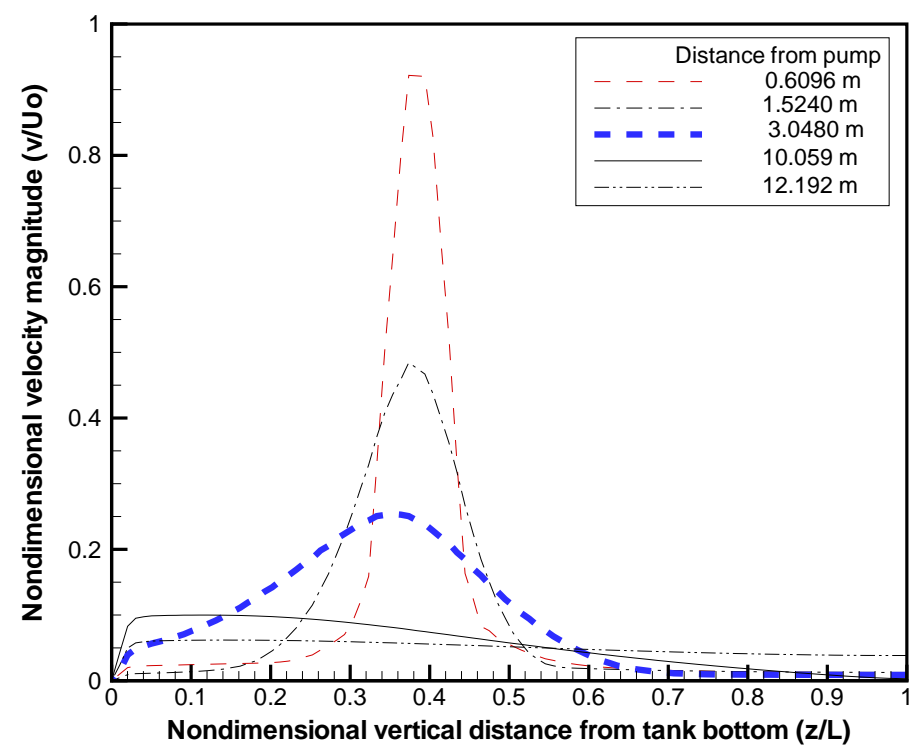

Figure 16. Steady-state nondimensional vertical velocity profiles for various distances from the pump along the principal discharge direction: 3D Model Results for the Full Tank Facility with a given liquid level $(\mathrm{L}=1.778 \mathrm{~m})$ 


\section{TANK MODEL AND ANALYSIS}

With the validity of the computational model established by comparison with the measured data, the model can now be applied to predict flow behavior in Tank 18.

\section{Effects of Tank Liquid Level and Pump Nozzle Elevation on Sludge Mixing}

Sludge removal capability was evaluated for two different liquid levels as listed in Table 1, $1.778 \mathrm{~m}$ and $1.016 \mathrm{~m}$. The results are compared in Fig. 17. The higher liquid level is generally more efficient. The results showed that the sludge removal capability is about the same within about $1.524 \mathrm{~m}$ of the pump (corresponding to about 10 nozzle diameters), but the velocity difference between the two cases becomes larger as the distance increases from $3.048 \mathrm{~m}$ to $12.192 \mathrm{~m}$ (near the wall boundary). This is mainly due to the momentum dissipation from the free surface in the case of the lower liquid level as shown in Figs. 18 21. Sensitivity results [3] show that for a given liquid level, a lower pump elevation provides better mixing performance based on a local velocity requirement for solid suspension. When the ADMP moves down to the tank floor from an elevation of about $0.7 \mathrm{~m}$, the overall hydraulic cleaning capability near the tank bottom increases by about 15\% as shown in Fig. 22.

\section{Effects of Pump Rotation on Sludge Mixing}

Sensitivity results show that rotational effects on flow patterns are negligible for the $1.016 \mathrm{~m}$ liquid level. Similar flow behavior is seen at the high liquid level. Graphical comparisons between the cases with and without pump rotation for both the discharge plane and the plane at $0.0762 \mathrm{~m}$ above the tank bottom are shown in Fig. 23.

It is important to recognize that local velocity is not the only parameter affecting the ability of the liquid stream to suspend sludge or aggregate materials. Tank sludge properties are equally important, especially when the sludge has a spatially non-uniform structure or is composed of cohesive aggregate. The length of time that the sludge is exposed to the liquid stream is often important in suspending cohesive sludge, and this effect is not captured in the present analysis. A longer exposure time, as would be the case for an indexed pump rather than a rotating pump, could reasonably be expected to result in greater 
suspension or erosion of the sludge layer at a given location. Exposure time for an indexed pump can be estimated from previous operating experience. Testing in kaolin clay indicated a three percent increase in the ECR when the pump was indexed.[6] Even so, separate quarter-scale pump testing indicated that better mixing was obtained during rotation.

\section{Effects of the Nozzle Diameter on Sludge Mixing}

A smaller nozzle diameter was evaluated to examine its effectiveness for sludge removal. A reduced flow rate $\left(9.84 \mathrm{~m}^{3} / \mathrm{min}\right.$ per nozzle) and a 0.0762-m nozzle diameter were evaluated. Figure 24 compares velocity distributions for the two nozzle diameters at the plane $0.0762 \mathrm{~m}$ (3 in) above the tank floor with no pump rotation. As shown in the figure, sludge mixing and removal would be improved by about $15 \%$ with the smaller nozzle, based solely on local velocity.

Turbulence intensity can be used as an indicator of local mixing to compare the ADMP and the smaller jet flows. The turbulence intensity $I$ is defined as the ratio of the root-mean-square of the velocity fluctuations to mean flow velocity. That is,

$I=\frac{\sqrt{\frac{1}{3}\left(u^{\prime 2}+V^{\prime 2}+w^{\prime 2}\right)_{\text {avg }}}}{V} \approx 0.8165 \frac{\sqrt{k}}{V}$

In Eq. (4) the turbulence intensity is proportional to the square root of the turbulent kinetic energy $k$ for a given mean fluid velocity. A comparison of the turbulence intensity distributions for the two jet mixers is shown in Fig. 25. The results show that the smaller mixer drives higher local velocities, thereby implying better sludge removal capability. The results shown in Figs. 24 and 25 indicate that the velocity reduction rate along the discharge direction increases with increasing turbulence intensity as shown in Fig. 26. This is mainly related to the increased radial dispersion of fluid momentum which leads to diminished axial velocity of the nozzle discharge flow. The results clearly show that a smaller mixer has better mixing performance under the same operating conditions in terms of jet flow dissipation into the stagnant fluid domain in tank. 


\section{Effects of Fluid Properties on Sludge Mixing}

Most analyses were performed using water at the reference operating conditions. A fluid with a different specific gravity listed in Table 1 was used to examine the sensitivity of the flow patterns to a change in specific gravity. Typically, the fluid above the sludge, known as supernate, has a specific gravity of less than 1.2. The sensitivity study considered ranges of specific gravity from 1 to 1.2 and viscosity from 1 to $2 \mathrm{cp}$. The results show that the flow patterns are not sensitive to this change in specific gravity. At the discharge plane, there are no apparent differences in flow evolution. At the lower elevation 0.0762 $\mathrm{m}$ above the tank floor, slurry flow around the horizontal discharge direction of the nozzle dies out slightly more quickly than for water. The radial flow behavior induced by the slurry is larger than that of water because of the increased diffusion in the momentum transport. However, when the ECR is defined as the distance over which the jet velocity exceeds the minimum suspension velocity, differences between water and slurry are negligible for the conditions considered here.

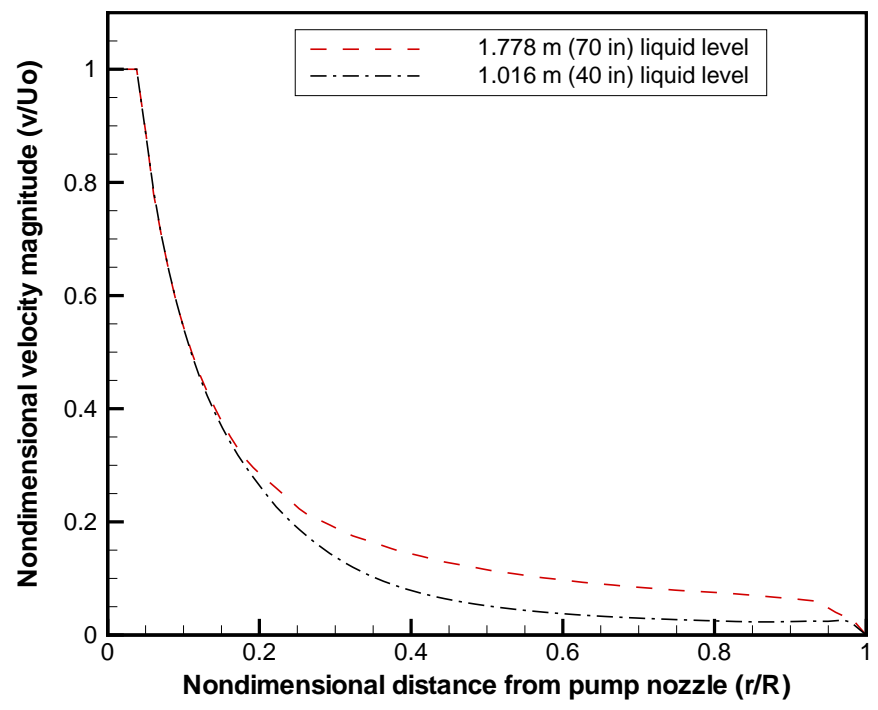

Figure 17. Nondimensional velocity profiles for various distances from the pump at the nozzle discharge plane located at $0.6858 \mathrm{~m}$ above the tank bottom 




Figure 18. Comparison of nondimensional velocity profiles for different tank liquid levels at $0.6096 \mathrm{~m}$ distance from the pump

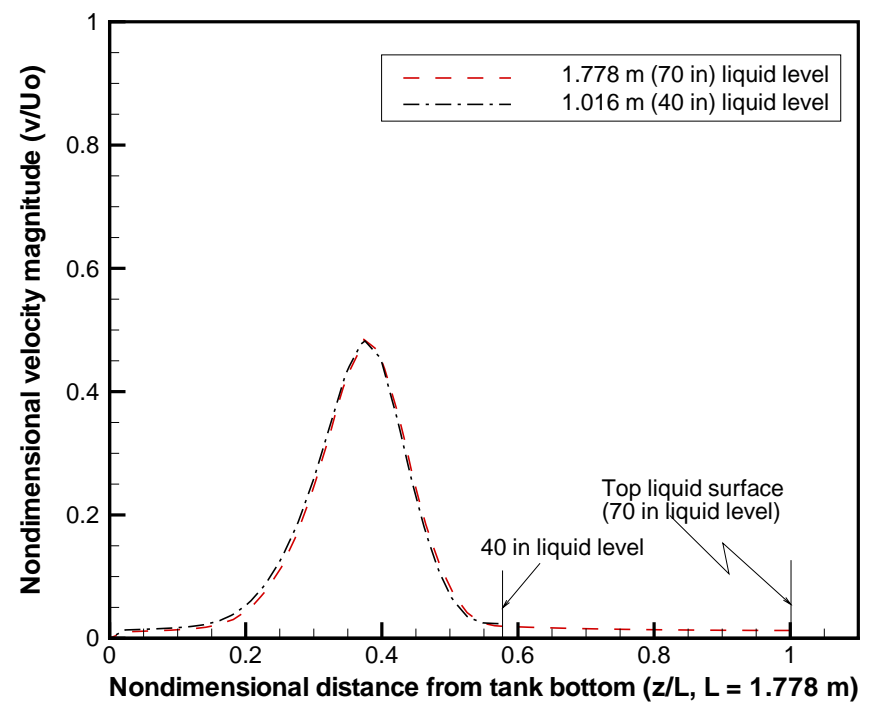

Figure 19. Comparison of nondimensional velocity profiles for different tank liquid levels at $1.5240 \mathrm{~m}$ distance from the pump 


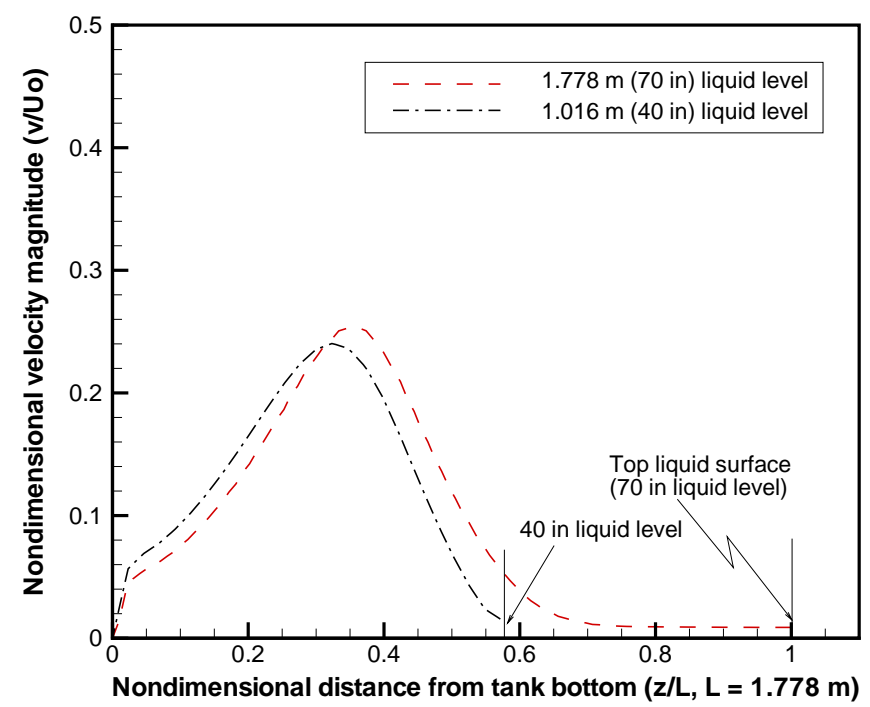

Figure 20. Comparison of nondimensional velocity profiles for different tank liquid levels at $3.0480 \mathrm{~m}$ distance from the pump



Figure 21. Comparison of nondimensional velocity profiles for different tank liquid levels at $\mathbf{1 2 . 1 9 2} \mathrm{m}$ distance from the pump 


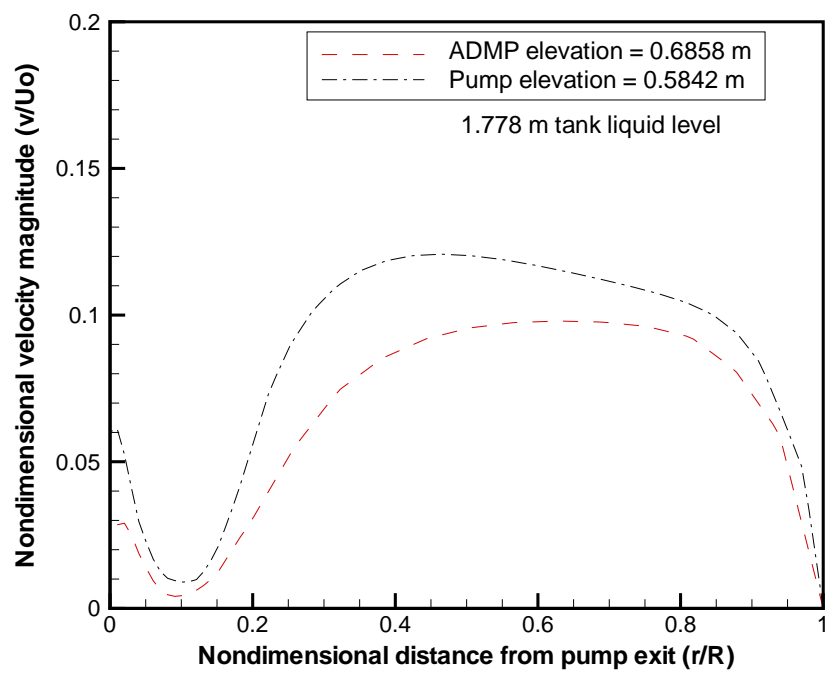

Figure 22. Comparison of nondimensional velocity profiles along the pump discharge direction for two different pump locations above tank bottom under the $1.778 \mathrm{~m}$ liquid level

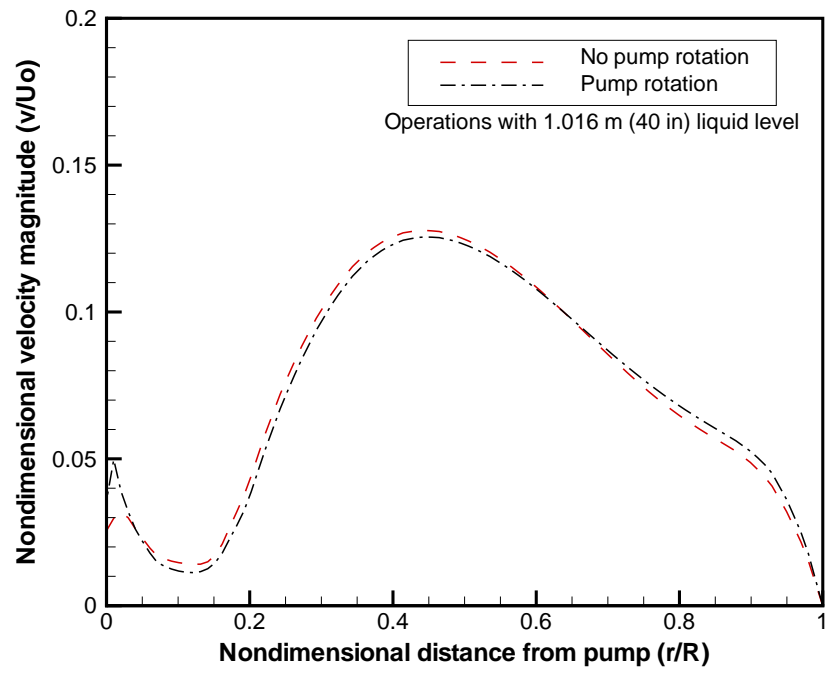

Figure 23. Downstream evolutions of Tank 18 ADMP with and without pump rotations for $1.016 \mathrm{~m}$ tank liquid level at the discharge plane $0.0762 \mathrm{~m}$ above the tank bottom. 




Figure 24. Comparison of horizontal velocity profiles along the downstream directions of the pump nozzles of Tank 18 with ADMP 0.1524-m mixer and a mixer with a 0.0762-m nozzle at the plane $0.0762 \mathrm{~m}$ above the tank bottom

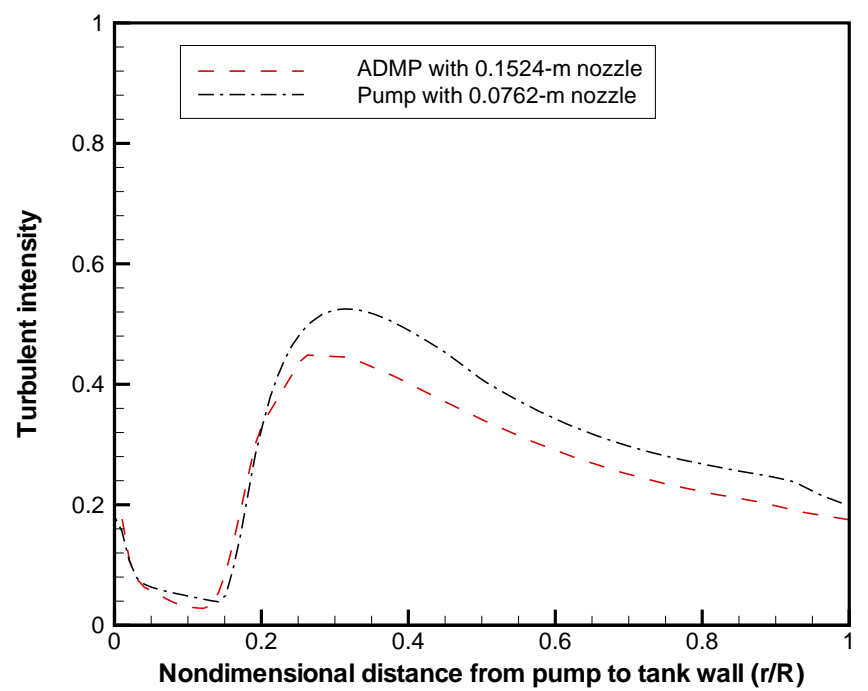

Figure 25. Comparisons of turbulence intensity profiles for the Tank 18 operations with ADMP and the smaller mixer at the plane $0.0762 \mathrm{~m}$ above the tank bottom 


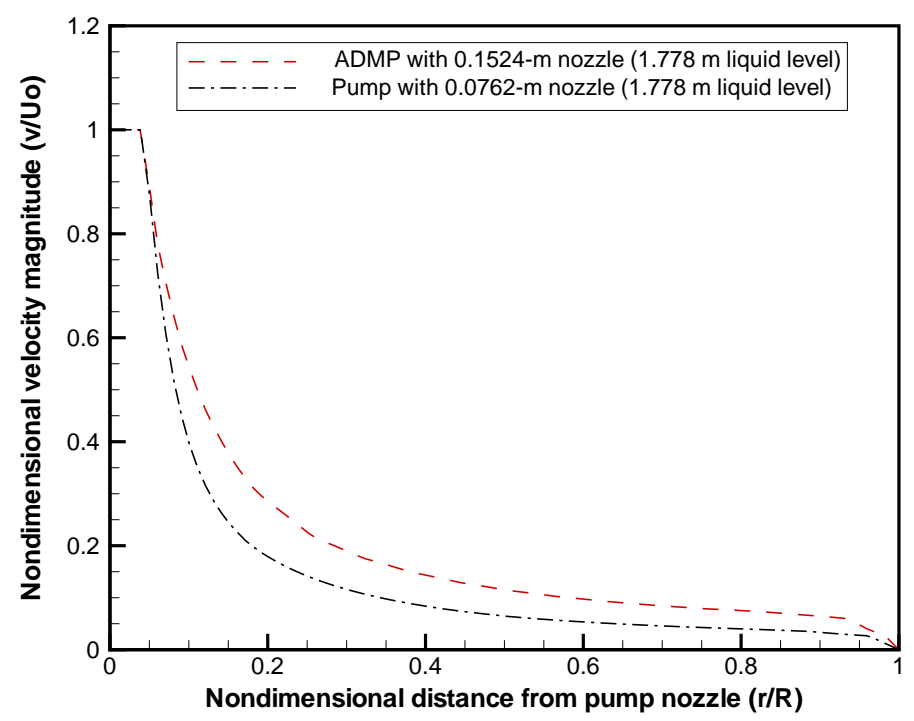

Figure 26. Comparison of horizontal velocity profiles along the downstream directions of the pump nozzles of Tank 18 with ADMP 0.1524-m mixer and a mixer with a 0.0762-m nozzle at the pump discharge plane $0.6858 \mathrm{~m}$ above the tank bottom

\section{SUMMARY AND CONCLUSIONS}

Tank simulation models with ADMP mixers have been developed. Calculations have been performed to benchmark the models with full tank facility test data and to assess the efficiency of sludge suspension and removal operations during steady-state and transient pump operations. Solid obstructions other than the pump components, and free surface motion of the tank liquid were neglected.

A three-dimensional analysis with a two-equation turbulence model was performed with FLUENT ${ }^{\mathrm{TM}}$. The computed results were validated with Full Tank Facility test and literature data. Rotational effects of the pump were considered to estimate the impact on sludge suspension and removal assuming that local fluid velocity can be used as a measure of slurrying and mixing efficiency. For a minimum suspension velocity of $0.7 \mathrm{~m} / \mathrm{sec}$, the results indicated that the existing ADMP mixer would provide adequate sludge removal from the tank with a 1.778-m liquid level except for a wall boundary region of about $0.6096 \mathrm{~m}$. 
The CFD simulation results for the ADMP mixer showed that steady-state flow patterns were reached within about 60 seconds. The results also showed that when the pump was rotated continuously in one direction, the operational time to reach steady-state conditions was much longer. In addition, when the pump is off-center, times to reach steady-state flow patterns are much longer than the case with the pump located at the tank center.

The main conclusions are as follows:

- Model predictions agree with test data within about $25 \%$. In the velocity ranges where sludge removal is required, the model provides a reasonable estimate when compared to actual test data. The predictions are in good agreement with wall jet data available in the literature.

- The difference between a fixed pump and a rotating pump is small, and is well within the uncertainty of the present calculations. A rotating pump is somewhat better than fixed because of secondary flows. The effect of pump rotation is more pronounced when the pump is located off-center and the tank liquid level is lower.

- A higher tank liquid level results in better sludge mixing.

- A smaller nozzle size with an identical $\mathrm{U}_{\mathrm{o}} \mathrm{d}_{\mathrm{o}}$ has better performance for suspending and removing the sludge.

- The maximum clearing distance is not sensitive to the slurry fluid properties when the ranges of fluid properties for 1 to 1.2 specific gravity and 1 to $2 \mathrm{cp}$ viscosity are considered.

- Local velocities adjacent to the tank wall are potentially lower than those needed to remove sludge.

- Two dimensional models of the flow are inadequate.

\section{NOMENCLATURE}

$\begin{array}{ll}C_{o}, C_{\mu} & \text { empirical constants } \\ \text { cp } & \text { centipoise (equal to } 0.001 \mathrm{~kg} / \mathrm{m} \text {-sec) } \\ \mathrm{D} & \text { tank diameter } \\ d_{0} & \text { nozzle diameter } \\ \mathrm{H} & \text { height }\end{array}$




\begin{tabular}{|c|c|}
\hline $\mathrm{ft}$ & foot $(0.3048 \mathrm{~m})$ \\
\hline g & gravitational acceleration \\
\hline I & turbulence intensity \\
\hline $\mathrm{k}$ & turbulent kinetic energy \\
\hline in & inch $(0.0254 \mathrm{~m})$ \\
\hline $\mathrm{L}$ & total distance \\
\hline $\mathrm{m}$ & meter \\
\hline $\mathrm{p}$ & pressure \\
\hline $\mathrm{R}$ & tank radius \\
\hline rpm & revolutions per minute \\
\hline sec & seconds \\
\hline SG & specific gravity \\
\hline SRS S & savannah River Site \\
\hline $\mathrm{t}$ & time \\
\hline$x, y, z$ & local distance from pump nozzle \\
\hline$U_{0}$ & nozzle exit velocity \\
\hline$V$ & mean velocity magnitude \\
\hline$u, v, w$ & local velocities in the $\mathrm{x}, \mathrm{y}$, and $\mathrm{z}$ directions \\
\hline$u^{\prime}, v^{\prime}, w^{\prime}$ & local velocity fluctuations in the $\mathrm{x}, \mathrm{y}$, and $\mathrm{z}$ directions \\
\hline$\varepsilon$ & rate of dissipation of turbulent kinetic energy \\
\hline$\varphi$ & nondimensional velocity \\
\hline$\eta$ & nondimensional axial distance from nozzle \\
\hline$\mu$ & dynamic viscosity \\
\hline$\rho$ & density \\
\hline$\tau$ & shear stress \\
\hline$\Omega$ & vorticity \\
\hline
\end{tabular}




\section{REFERENCES}

1. Lee, S. Y., Dimenna, R. A., Stefanko, D. B., Leishear, R. A., 2004, “Mixing in Large Scale Tanks - Part I, Flow Modeling of turbulent Mixing Jets," ASME Heat Transfer / Fluids Engineering Conference, Charlotte, N. C., July 11 - 15.

2. Stefanko, D. B., Leishear, R. A., Dimenna, R. A. and Lee, S. Y., 2004, “Mixing in Large Scale Tanks Part II, Full Scale Pump Testing”, 2004 ASME Heat Transfer / Fluids Engineering Summer Conference, Charlotte, N. C., July $11-15$.

3. Lee, S. Y. and Dimenna, R. A., 2001, "Performance Analysis for Mixing Pumps in Tank 18”, WSRCTR-2001-00391.

4. Augeri, M. J., Hubbard, M. and Thomas, J. L., 2004, "Mixing in Large Scale Tanks - Part IV, Cleaning Nuclear Waste From Tanks”, 2004 ASME Heat Transfer / Fluids Engineering Summer Conference, Charlotte, N. C., July $11-15$.

5. Abramovich, G. N., 1963, “The Theory of Turbulent Jets”, The MIT Press, Cambridge, MA.

6. Kiser, K. M., 1963, "Material and Momentum Transport in Axisymmetric Turbulent Jets of Water", A.I.Ch.E. Journal, Vol. 9, No. 3, pp. 386-390.

7. Abdel-Rahman, A., Chakroun, W., and Al-Fahed, S., 1997, "LDA Measurements in the Turbulent Round Jet,” Mech. Res. Commun., Vol. 24, pp. 277-288.

8. Post, S., 1998, “A Computational and Experimental Study of Near-Field Entrainment in Steady Gas Jets,” MSME thesis, Purdue University.

9. Swamy, C. N. V. and Bandyopadhyay, P., 1975, "Mean and Turbulence Characteristics of ThreeDimensional Wall Jets”, J. of Fluid Mechanics, Vol. 71, Part 3, pp. 541-562.

10. Dallavalle, J. M., 1948, Micromeritics, $2^{\text {nd }}$ Edition, Pitman Publishing Corporation, New York.

11. Graf, W. H., 1971, Hydraulics of Sediment Transport, McGraw-Hill Book Company.

12. R. A. Leishear, D. B. Stefanko, R. A. Dimenna, and S. Y. Lee, "Mixing in Large Scale Tanks - Part III, Predicting Slurry Pump Performance”, 2004 ASME Heat Transfer / Fluids Engineering Summer Conference, Charlotte, N. C., July 11 - 15, 2004. 
13. Poirier, M. R., Powell, M. R., Gladki, H., and Rodwell, P. O., 1999, "Suspending Zeolite Particles in Tanks”, $7^{\text {th }}$ International Symposium on Liquid-Solid Flows, Joint ASME-JSME Joint Meeting, July $18-23$.

14. VPF 22731, Lawrence Pumps. Inc., Advanced Design Mixer Pump, Vendor drawings for Westinghouse Savannah River Corporation, S.C..

15. Marsh McBirney Inc., 1977, “Instruction Manual, Model 511, Electromagnetic Water Current Meter”, Frederick, MD.

16. Personal communications with Marsh-McBirney, Inc., Company Address: 4539 Metropolitan Ct., Frederick, MD 21704, Phone Number: (800) 368-2723, Fax Number: (301) 874-2172 e-mail: www.Marsh-McBirney.com

17. Strawberry Tree Data Acquisition and Control Catalogue, Computer Instrumentation and Controls, “Instruction Manual”, Strawberry Tree Corp., CA.

18. FLUENT Manual, Fluent, Inc., 1998.

19. Madina, C. K., and Bernal L. P., 1994, "Interaction of a Turbulent Round Jet with the Free surface”, Journal of Fluid Mechanics, Vol. 261, pp. 305-332.

20. Jones, W. P. and Launder, P. E., 1972, “The Prediction of Laminarization with a Two-Equation Model of Turbulence”, Int. J. of Heat and Mass Transfer, Vol. 15, pp. 301-314.

21. Nielsen, P. V., Restivo, A., and Whitelaw, J. H., 1978, “The Velocity Characteristics of Ventilated Rooms”, J. of Fluids Engineering, Vol. 100, pp. 291-298. 